\title{
Role of extracorporeal membrane oxygenation in pediatric cancer patients: a systematic review and meta-analysis of observational studies
}

Valerie Slooff', Rianne Hoogendoorn'1, Jeppe Sylvest Angaard Nielsen², John Pappachan', Angela Amigoni ${ }^{4}$, Fabio Caramelli ${ }^{5}$, Omer Aziz ${ }^{6}$, Enno Wildschut ${ }^{7}$, Sascha Verbruggen ${ }^{7}$, Roman Crazzolara ${ }^{8}$, Christian Dohna-Schwake $^{9}$, Jenny Potratz ${ }^{10}$, Jef Willems ${ }^{11}$, Judit Llevadias ${ }^{12}$, Andrea Moscatelli ${ }^{13}$, Alessia Montaguti ${ }^{13}$, Gabriella Bottari ${ }^{14}$, Matteo Di Nardo ${ }^{14}$, Luregn Schlapbach ${ }^{15}$ and Roelie Wösten-van Asperen ${ }^{1 *}$ on behalf of the POKER (PICU Oncology Kids in Europe Research group) research consortium of ESPNIC (European Society of Paediatric Neonatal Intensive Care)

\begin{abstract}
Background: The use of extracorporeal membrane oxygenation (ECMO) in pediatric patients with underlying malignancies remains controversial. However, in an era in which the survival rates for children with malignancies have increased significantly and several recent reports have demonstrated effective ECMO use in children with cancer, we aimed to estimate the outcome and complications of ECMO treatment in these children.

Methods: We searched MEDLINE, Embase and CINAHL databases for studies on the use ECMO in pediatric patients with an underlying malignancy from inception to September 2020. This review was conducted in adherence to Preferred Reporting Items for Systematic Review and Meta-Analysis statement. Study eligibility was independently assessed by two authors and disagreements resolved by a third author. Included studies were evaluated for quality using the Newcastle-Ottawa Scale (NOS). Random effects meta-analyses (DerSimonian and Laird) were performed. The primary outcomes were mortality during ECMO or hospital mortality.
\end{abstract}

Results: Thirteen retrospective, observational cohort studies were included, most of moderate quality (625 patients). The commonest indication for ECMO was severe respiratory failure (92\%). Pooled mortality during ECMO was 55\% (95\% confidence interval [Cl], 47-63\%) and pooled hospital mortality was 60\% (95\% Cl 54-67\%). Although heterogeneity among the included studies was low, confidence intervals were large. In addition, the majority of the data were derived from registries with overlapping patients which were excluded for the meta-analyses to prevent resampling of the same participants across the included studies. Finally, there was a lack of consistent complications reporting among the studies.

\footnotetext{
*Correspondence: r.m.vanasperen@umcutrecht.nl

${ }^{1}$ Department of Pediatric Intensive Care, University Medical Centre Utrecht/Wilhelmina Children's Hospital, Lundlaan 6, 3584 EA Utrecht, The Netherlands

Full list of author information is available at the end of the article
} original author(s) and the source, provide a link to the Creative Commons licence, and indicate if changes were made. The images or other third party material in this article are included in the article's Creative Commons licence, unless indicated otherwise in a credit line to the material. If material is not included in the article's Creative Commons licence and your intended use is not permitted by statutory regulation or exceeds the permitted use, you will need to obtain permission directly from the copyright holder. To view a copy of this licence, visit http://creativecommons.org/licenses/by/4.0/. 
Conclusion: Significantly higher mortalities than in general PICU patients was reported with the use of ECMO in children with malignancies. Although these results need to be interpreted with caution due to the lack of granular data, they suggest that ECMO appears to represents a viable rescue option for selected patients with underlying malignancies. There is an urgent need for additional data to define patients for whom ECMO may provide benefit or harm.

Keywords: Extracorporeal membrane oxygenation, Pediatric intensive care unit, Cancer, Outcomes, Systematic review, Meta-analysis

\section{Introduction}

The prognosis of children with malignancies has improved significantly over the past two decades. Precision medicine and immunotherapy along with other new therapies have translated into improved survival and cure rates. Currently, 5 -year all-cancer survival is almost $80 \%$ in children [1]. However, intensified treatment protocols have resulted in more complications, leading to a growing number of children requiring admission to a pediatric intensive care unit (PICU). In this context, identifying patients who are most likely to benefit from invasive organ support is crucial. Defining the optimal timing of these life-sustaining therapies is one of the top five research priorities identified by a recent Delphi survey among pediatric intensivists and oncologists [2].

Patients who fail conventional pulmonary and/or circulatory support may be considered for extracorporeal membrane oxygenation (ECMO). The use of ECMO in children with underlying malignancies has historically been contraindicated; however, several recent reports have demonstrated its effectiveness in selected cases. In addition, children with malignancies are becoming more prevalent in the Extracorporeal Life Support Organization (ELSO) registry which collates data from 422 pediatric ECMO centers worldwide [3]. The indications for ECMO are expanding, but is effectiveness and the rate of associated complications in high-risk populations such as children with malignancy is poorly described. Most of the existing data come from small, single-center retrospective studies.

Given the controversial nature of this use of ECMO, this systematic review and meta-analysis was designed to describe the characteristics of children with an underlying malignancy receiving ECMO and the complications and survival rates observed.

\section{Methods}

\section{Search strategy and selection criteria}

We conducted a systematic review and meta-analysis using the Preferred Reporting Items for Systematic Reviews and Meta-analyses (PRISMA) recommendations (Additional file 1: Table S1) [4]. It was anticipated that the majority of studies would be observational, so we followed the guidelines of reporting systematic reviews and meta-analysis of observational studies $[5,6]$.

Two investigators (VS and $\mathrm{RH}$ ) performed a comprehensive literature search of MEDLINE, Embase, and CINAHL databases from inception to September 30, 2020. Databases were electronically searched for relevant publications using combinations of the following medical subject headings (MeSH) and keywords "Extracorporeal membrane oxygenation" AND "Neoplasms" AND "Pediatric" (Additional file 1: Table S2). In addition, a hand search of the references in included full texts was performed to identify additional articles for inclusion.

Articles were included if they reported outcomes for pediatric oncology patients who were supported on ECMO. If a study also included non-oncology patients, but a clearly defined subset of pediatric oncology patients was described, we included the study, but only collected data from these oncology patients. In addition, for studies that included overlapping patients (period of overlap $>1$ year) from the same registry, the largest study was included in the meta-analysis, while the rest of the studies were included in the review. Only studies published in English were considered for inclusion. We excluded studies that included only adult patients, review articles, conference proceedings, correspondence, case reports, publications in abstract form only, and editorials. In addition, for studies including children supported by ECMO following hematopoietic stem cell transplantation (HSCT), only those in which data on HSCT performed for malignant diseases was reported were included.

\section{Data extraction and quality analysis}

Abstracts of studies identified were screened, and those that met the inclusion criteria underwent full-text review by two independent investigators (VS and RH). Disagreements were reviewed by a third reviewer (RW), who had a deciding vote. Data for study design, patient characteristics, interventions, and study outcomes were abstracted independently and in duplicate.

The quality of the included studies was assessed by using the Newcastle-Ottawa Scale for observational studies $[7,8]$. The scale evaluates three domains of bias: selection of participants (i.e., representativeness of the cohorts, ascertainment of exposure, and outcome of 
interest not being present at the start of study), comparability (to account for confounders that might influence the outcome of interest), and measure outcomes (i.e., methods for outcome assessment, appropriateness of the length of time to assess the outcome, and losses to follow-up that might compromise validity). This scale consists of a grading system with a maximum score of 9. A score of $\geq 7$ points indicates that a study is of high quality $[7,8]$. We used the Grading of Recommendations, Assessments, Developments and Evaluations (GRADE) system to assess the certainty of evidence $[9,10]$.

\section{Outcomes}

The primary outcome was mortality on ECMO and at hospital discharge. Secondary outcomes included duration of ECMO and complications while on or associated with ECMO.

\section{Data analysis}

Descriptive statistics were reported as medians and IQRs for continuous variables and counts and percentages for categorical variables. As we anticipated considerable between-study heterogeneity, an inverse-variance weighted random-effects model was used to pool effect sizes as suggested by DerSimonian and Laird [11]. Mortality outcomes were presented as proportions. In the case of overlapping patient data, we included the largest study and excluded overlapping studies in the meta-analysis.

Heterogeneity among studies was assessed with the $I^{2}$ measure, where $I^{2}>50 \%$ suggests substantial heterogeneity $[12,13]$. We subsequently performed sensitivity analyses to determine the influence of individual studies on the overall effect, including a leave-one-out analysis which iteratively removed one study at a time, generating Baujat plots, and influence diagnostics [14, 15]. Publication bias was assessed by constructing a funnel plot and by using the Egger's test [16].

All statistical analyses were performed in $\mathrm{R}$ studio (Version 4.0.5, R studio, Inc. Boston) using the 'meta' and 'dmetar' packages [17, 18].

\section{Results}

Our search retrieved 704 citations, 77 of which were selected for full-text review (Fig. 1). Thirteen studies with a combined population of 625 patients fulfilled our inclusion criteria - all were observational, retrospective studies (Table 1) [19-31]. Four studies, all from the ELSO registry, had potential overlapping information, although inclusion criteria varied between the studies $[20,21,23$, 25]. Eleven studies reported the underlying oncological diagnosis, with a predominance of hematological malignancies (Additional file 1: Table S3) [19-24, 26-30]. Four studies included HSCT patients [20, 24, 27, 28]; however, none of these studies specified the characteristics of this subgroup separately. One study included exclusively HSCT patients [23]. Studies varied with respect to criteria for initiation of ECMO, but the commonest indication was respiratory failure. The number of patients ranged from 4 to 200 per study. Six studies included patients with non-respiratory indications for the initiation of ECMO, including sepsis $(n=9)$, cardiac failure $(n=17)$, and extracorporeal cardiopulmonary resuscitation $(n=10)$ (Additional file 1: Table S4) [21, 23, 24, 27-29].

\section{Primary outcome: ECMO and hospital mortality}

Nine studies reported mortality during ECMO [19, 21$24,26,27,29,31]$. Two studies retrieved their data from the ELSO registry with overlapping study periods [21, 23]. We included the largest study for the meta-analysis [21]. When data from the studies were pooled, mortality during ECMO among 173 patients was 55\% (95\% CI 47-63\%) (Fig. 2). There was low heterogeneity among the studies $\left(I^{2} 0 \%\right)$; however, the confidence interval was large (95\% CI 0.0-67.6). Influence analysis revealed one study that was influential [21] (Additional file 1: Figure S1). After excluding this study, the remaining eight studies had 59 patients with a cumulative pooled mortality of 49\% (95\% CI 35-63\%) (Additional file 1: Figure S2 and Table S5).

Twelve studies reported hospital mortality [19-30]. Four studies extracted data on hospital mortality from the ELSO registry [20, 21, 23, 25]. Due to overlapping study periods, we included the largest study [25] in the meta-analysis. Pooled hospital mortality of nine studies among 420 patients was 60\% (95\% CI 54-67\%) (Fig. 3). There was low heterogeneity among the studies $\left(I^{2} 6 \%\right)$; however, the CI was large (95\% CI 0-67\%). We identified two studies that were influential $[25,30]$ (Additional file 1: Figure S3). After excluding these two studies, the pooled hospital mortality among 66 patients was 50\% (95\% CI 37-63\%) (Additional file 1: Figure S4 and Table S6).

\section{Pre-ECMO characteristics and secondary outcomes}

Reporting on pre-ECMO variables and complications was inconsistent across the included studies. Therefore, data were not pooled. All patients had severe acute respiratory distress syndrome (ARDS), as reflected by $\mathrm{PaO}_{2} / \mathrm{FiO}_{2}$ ratio or oxygenation index (Table 2). Eight studies reported days on mechanical ventilation before ECMO was initiated, showing a range from several hours to 10 days [19-21, 23, 24, 26, $27,29]$. The total duration of ECMO varied between 1 and 72 days. Only two studies reported severity of illness scores prior to ECMO $[24,28]$. However, different 


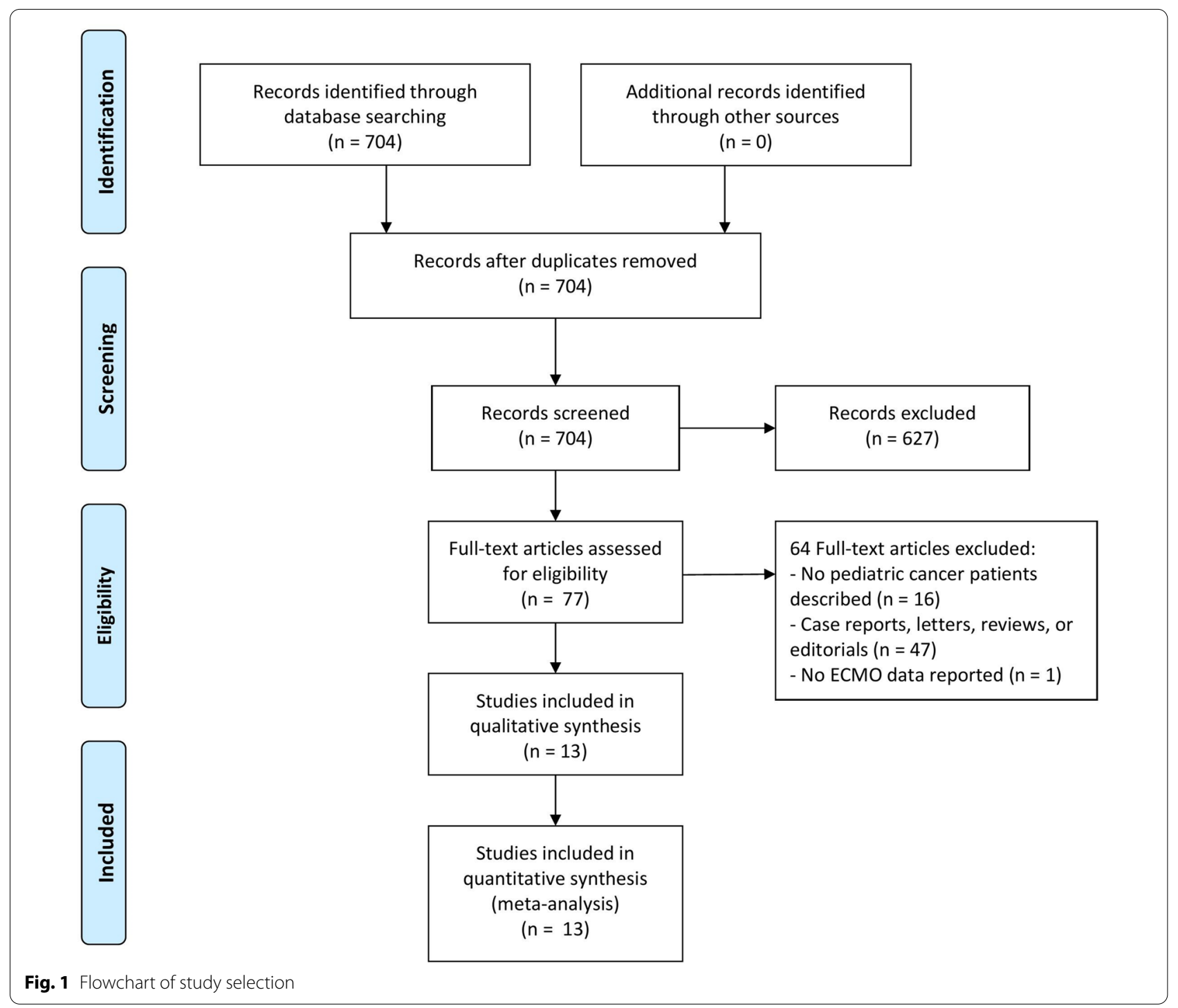

scores were used, making a comparison between both studies impossible. Surprisingly, scarce data on cancer type and stage, details of HSCT trajectory, and cancer treatment prior to PICU admission were provided.

Eight studies included data for complications [19, $21,22,24,26-29]$ (Table 2). In view of the inconsistent reporting of these outcomes across the included studies, the adverse events were not pooled. Sixty-nine $(36.5 \%)$ of 189 patients in nine studies had major hemorrhages. In 49 patients (26\%), new infections during ECMO therapy were reported. One hundred and nine patients $(57.7 \%)$ required renal replacement therapy on ECMO. The number of circuit-associated or cannula-associated complications was low.

\section{Risk of bias}

Of the 13 studies, 8 had a total Newcastle-Ottawa Scale score $<7$ (Additional file 1: Table S7) [19, 21-24, 26, 27, 29]. None of the studies reported comparative clinical data from unexposed groups. In 11 studies, the population was representative or somewhat representative of the average population. In all studies, the assessment of outcome was confirmed with medical records or linked through a database and the follow-up of the patients was considered adequate.

Egger's test and funnel plots showed some, non-significant, evidence of publication bias (Additional file 1: 
Table 1 Characteristics of included studies

\begin{tabular}{|c|c|c|c|c|c|}
\hline Study & Country & Period & Study design & Inclusion criteria & $\begin{array}{l}\text { ECMO group of children } \\
\text { with underlying } \\
\text { malignancies }\end{array}$ \\
\hline Lindén et al. 1999 [19] & Sweden & NR & Retro, single center & $\begin{array}{l}\text { Underlying malignancy and } \\
\text { PCP pneumonia }\end{array}$ & 4 \\
\hline Gupta et al. 2008 [20] & ELSO registry & 1985-2004 & Retro, multicenter ELSO registry & $\begin{array}{l}\text { Immunocompromised condi- } \\
\text { tion and respiratory failure as } \\
\text { indication for ECMO } \\
\text { Age } 30 \text { days-19 yrs }\end{array}$ & 60 \\
\hline Gow et al. 2009 [21] & ELSO registry & 1992-2007 & Retro, multicenter ELSO registry & $\begin{array}{l}\text { Underlying malignancy } \\
\text { Age }<21 \text { yrs }\end{array}$ & 107 \\
\hline Meister et al. 2009 [22] & Austria & NR & Retro, single center & Leukemia & 4 \\
\hline Di Nardo et al. 2014 [23] & ELSO registry & $1991-2012$ & Retro, multicenter ELSO registry & $\begin{array}{l}\text { HSCT patients } \\
\text { Age }<18 \text { yrs }\end{array}$ & 15 \\
\hline Smith et al. 2016 [24] & Australia & 1993-2014 & Retro, single center & $\begin{array}{l}\text { Pediatric cancer patients with } \\
\text { neutropenic sepsis }\end{array}$ & 9 \\
\hline Bailly et al. 2017 [25] & ELSO registry & $2001-2013$ & Retro, multicenter ELSO registry & $\begin{array}{l}\text { ECMO for respiratory failure } \\
\text { due to a primary pulmonary } \\
\text { diagnosis } \\
\text { Age } 7 \text { days-18yrs }\end{array}$ & 161 \\
\hline Cortina et al. 2018 [26] & Austria & 2004-2007 & Retro, single center & Leukemia & 9 \\
\hline Maue et al. 2019 [27] & USA & $2011-2016$ & Retro, single center & $\begin{array}{l}\text { Pediatric oncology and/or HSCT } \\
\text { patients }\end{array}$ & 5 \\
\hline Steppan et al. 2020 [28] & USA & $2011-2018$ & $\begin{array}{l}\text { Retro, multicenter PEDECOR } \\
\text { registry }\end{array}$ & $\begin{array}{l}\text { Pediatric oncology and/or HSCT } \\
\text { patients }\end{array}$ & 16 \\
\hline Ranta et al. 2020 [29] & Sweden & 2008-2016 & Retro, multicenter & Hematological malignancies & 12 \\
\hline Coleman et al. 2020 [30] & USA & 2004-2013 & Retro, multicenter PHIS registry & $\begin{array}{l}\text { Underlying malignancy, genetic } \\
\text { disorders or high-risk congeni- } \\
\text { tal heart disease }\end{array}$ & 200 \\
\hline Friedman et al. 2020 [31] & USA & $2011-2016$ & Retro, multicenter & $\begin{array}{l}\text { Patients requiring WV-ECMO } \\
\text { Age } 14 \text { days- } 18 \text { yrs }\end{array}$ & 23 \\
\hline
\end{tabular}

ECMO extracorporeal membrane oxygenation, ELSO registry extracorporeal life support organization registry including $>145$ centers worldwide, $H S C T$ hematopoietic stem cell transplantation, $P C P$ Pneumocystis carinii pneumonia, Retro retrospective, yrs year

\begin{tabular}{|c|c|c|c|c|}
\hline Study & Non-survivors & Total & Weight & Mortality (proportion [95\% C \\
\hline Lindén et al., 1999 & 1 & 4 & $1.8 \%$ & $0.25[0.01 ; 0.81]$ \\
\hline Gow et al., 2009 & 62 & 107 & $63.0 \%$ & $0.58[0.48 ; 0.67]$ \\
\hline Meister et al., 2009 & 2 & 4 & $2.4 \%$ & $0.50[0.07 ; 0.93]$ \\
\hline Smith et al., 2016 & 5 & 9 & $5.4 \%$ & $0.56[0.21 ; 0.86]$ \\
\hline Cortina et al., 2018 & 4 & 9 & $5.4 \%$ & $0.44[0.14 ; 0.79]$ \\
\hline Maue et al., 2019 & 4 & 5 & $1.9 \%$ & $0.80[0.28 ; 0.99]$ \\
\hline Ranta et al, 2020 & 4 & 12 & $6.4 \%$ & $0.33[0.10 ; 0.65]$ \\
\hline Friedman et al, 2020 & 13 & 23 & $13.7 \%$ & $0.57[0.34 ; 0.77]$ \\
\hline Total $(95 \% \mathrm{Cl})$ & & 173 & $100.0 \%$ & $0.55[0.47 ; 0.63]$ \\
\hline
\end{tabular}

Heterogeneity: $\mathrm{Tau}^{2}=0 ; \mathrm{Chi}^{2}=5.36, \mathrm{df}=7(\mathrm{P}=0.62) ; \mathrm{I}^{2}=0 \%$

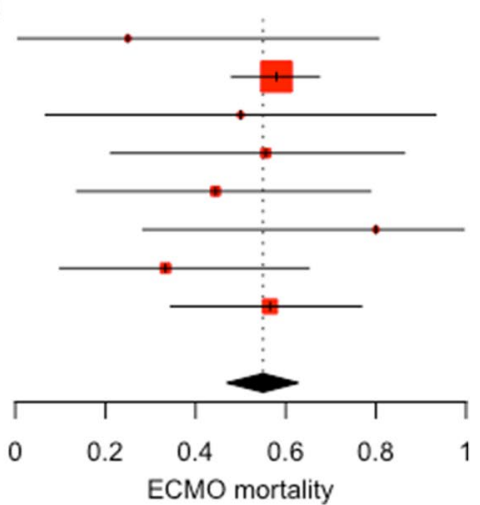

Fig. 2 Forest plot of mortality on ECMO for pediatric cancer patients using a random-effects model. Individual mortality for each study and the pooled weighted estimate shown with $95 \%$ confidence intervals (Cl). Vertical dotted line represents the pooled weighted estimate 


\begin{tabular}{|c|c|c|c|c|}
\hline Study & Non-survivors & Total & Weight & Mortality (proportion [95 \\
\hline Lindén et al., 1999 & 1 & 4 & $1.0 \%$ & $0.25[0.01 ; 0.81]$ \\
\hline Meister et al., 2009 & 2 & 4 & $1.3 \%$ & $0.50[0.07 ; 0.93]$ \\
\hline Smith et al., 2016 & 5 & 9 & $2.9 \%$ & $0.56[0.21 ; 0.86]$ \\
\hline Bailly et al, 2017 & 101 & 161 & $38.0 \%$ & $0.63[0.55 ; 0.70]$ \\
\hline Cortina et al., 2018 & 5 & 9 & $2.9 \%$ & $0.56[0.21 ; 0.86]$ \\
\hline Maue et al., 2019 & 5 & 5 & $0.6 \%$ & $1.00[0.48 ; 1.00]$ \\
\hline Steppan et al., 2020 & 6 & 16 & $4.9 \%$ & $0.38[0.15 ; 0.65]$ \\
\hline Ranta et al, 2020 & 6 & 12 & $3.9 \%$ & $0.50[0.21 ; 0.79]$ \\
\hline Coleman et al, 2020 & 126 & 200 & $44.4 \%$ & $0.63[0.56 ; 0.70]$ \\
\hline otal $(95 \% \mathrm{Cl})$ & & 420 & $100.0 \%$ & $0.60[0.54 ; 0.67]$ \\
\hline
\end{tabular}

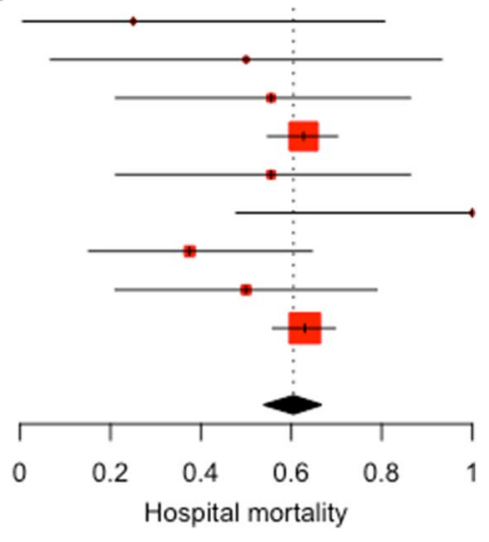

Fig. 3 Forest plot of hospital mortality for pediatric cancer patients who were supported on ECMO. Individual mortality for each study and the pooled weighted estimate shown with $95 \%$ confidence intervals (CI). Vertical dotted line represents the pooled weighted estimate

Figures S5 and S6, Table S8). A summary of the GRADE assessment for certainty of evidence is provided in Additional file 1: Table S9.

\section{Discussion}

To our knowledge, our systematic review is the first in which the results of ECMO in pediatric oncology patients are described. As overall pediatric cancer survival has improved and increasingly complex patients are successfully supported with ECMO, interest has grown concerning ideal use of ECMO in this population.

A recent large pediatric registry study of 9194 children between 2004 and 2013 who were supported on ECMO reported an overall final discharge mortality of $44 \%$ [30]. The pooled mortality (during ECMO 55\% and in hospital 60\%) in our meta-analysis is higher, but the mortality rates varied widely from 25 to $93 \%$. In addition, of the 625 patients identified, we only included mortality data from about $50 \%$ of these patients due to overlap between the included studies. We therefore should exercise caution in interpreting the results of our study. The higher mortality found in our meta-analysis may be explained by reduced baseline cardiopulmonary reserves due to treatment toxicities, prolonged recovery and vulnerability to all ECMO complications of pediatric cancer patients. Additionally, the inclusion of HSCT patients in a part of the included studies may have resulted in high mortality rates as HSCT has been identified as an independent risk factor for mortality in previous studies [32]. Presence of sepsis, acidosis, multi-organ dysfunction and higher severity of illness scores prior to ECMO are risk factors for mortality and are more common in oncology and HSCT patients $[21,33,34]$. Only a few studies included patients with non-respiratory indications for the initiation of ECMO, including sepsis, cardiac failure, and extracorporeal cardiopulmonary resuscitation. A recent meta-analysis showed a cumulative pooled estimate survival of $55 \%$ in septic children requiring ECMO [18]. However, due to small patient numbers, we were not able to conduct subgroup analyses to determine pooled mortality rates for the patient groups included in our study. The lack of granular data on all these factors in the included studies emphasizes the need for prospective studies to enable a more detailed analysis identifying risk factors for poor outcome.

In a recent systematic review, we showed that children with an underlying malignancy who require invasive mechanical ventilation have a mortality rate of $24 \%$ [35]. All of the children receiving ECMO in our present review had severe ARDS with median $\mathrm{PaO}_{2} / \mathrm{FiO}_{2}$ ratios below 100 or median OIs between 19 and 52 prior to start of ECMO. There are several studies that have shown an independent association of $\mathrm{OI}>40$ with higher mortality $[36,37]$. In addition, a recent review on ventilation parameters before initiation of ECMO in general pediatric patients who required ECMO for respiratory indications showed that both OI and duration of mechanical ventilation before ECMO were independently associated with in-hospital mortality [38]. The severe degree of oxygenation disturbances prior to ECMO reported in the included studies may reflect a reluctance among treating physicians to either refer for or place such children on ECMO leading to it use as a last resort. Future studies examining pre-ECMO data and mechanical ventilation parameters in a more granular manner will help in clinical decision making and counseling. Whether earlier application of ECMO may improve outcome of these patients is extremely important. A recent systematic 


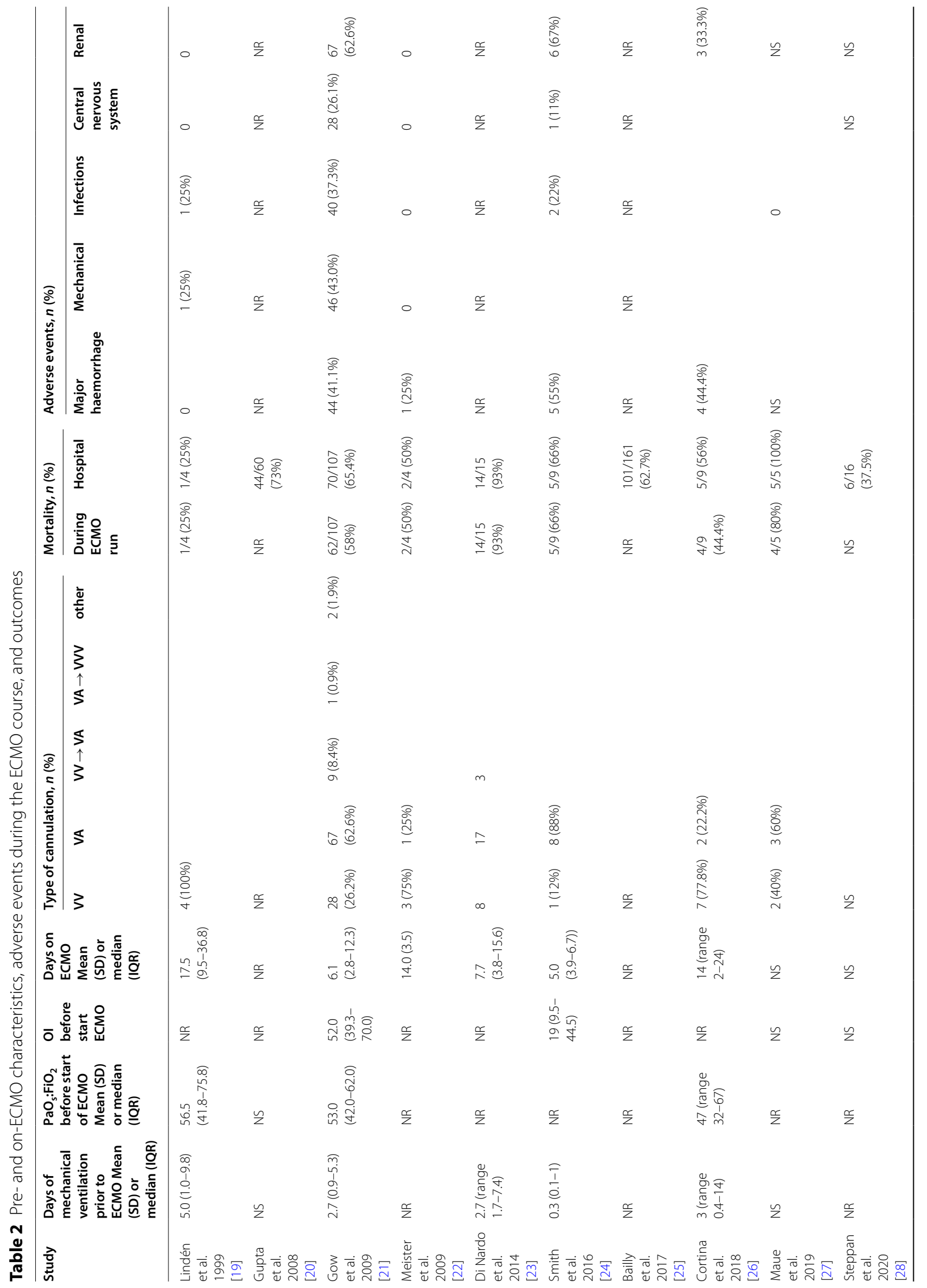




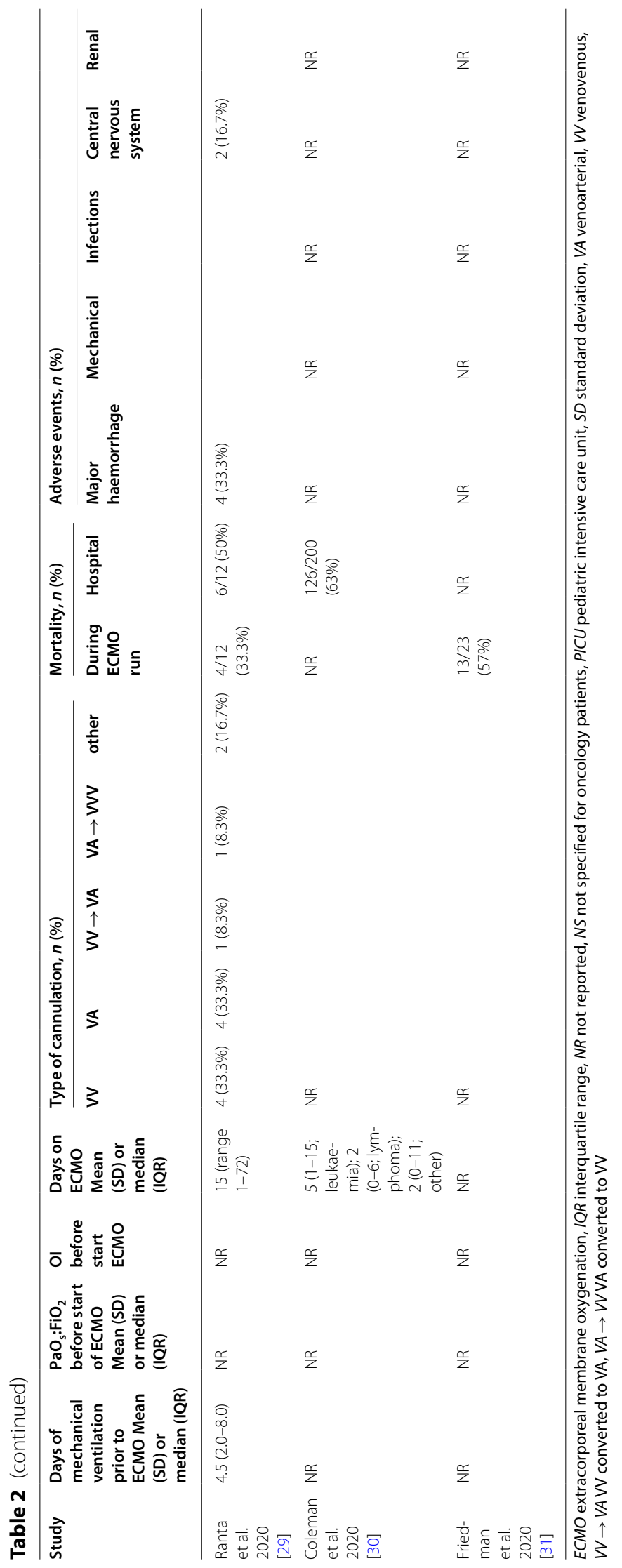


review and meta-analysis of ECMO in adults with severe ARDS showed that compared with conventional mechanical ventilation, the use of ECMO was associated with reduced 60-day mortality [39]. However, ECMO was also associated with a moderate risk of major bleeding. There are no studies comparing ECMO with conventional ventilation in children with PARDS. We cannot reach robust conclusions yet on ECMO timing in children based on the available evidence. Thus, caution should be used when evaluating ECMO candidacy.

The use of ECMO in patients with cancer poses considerable challenges. Patients with malignancies often have abnormal myeolopoiesis either as a consequence of the underlying malignancy or its treatment that results in thrombocytopenia and leukopenia with or without neutropenia. These patients are often also coagulopathic and the need for systemic anticoagulation increases the risk of bleeding. We found an ECMO-related complication rate of $65 \%$ which is comparable to the rate of $66 \%$ reported in a mixed group of children receiving ECMO [40]. Bleeding complications were somewhat higher to that found in children without oncologic disease supported on ECMO in a recent ELSO report [41]. Importantly, despite the high prevalence of cytopenia and immunosuppressive therapy among these patients, the incidence of nosocomial infection was similar to that seen in immunocompetent children. However, data on the presence of leukopenia and lower platelet counts were lacking in the majority of the included studies. Therefore, the incidence of cytopenia and the association with complications among the included patients could not be determined. These data and the increasing reports of children with malignancies in international ECMO registries suggest an underlying malignancy should not be considered a contraindication to ECMO.

Although this is the first systematic review carried out on children with cancer on ECMO, it has some limitations. The majority of studies included used registry data from which it is impossible to capture relevant, granular data. In addition, due to inconsistent reporting, we were not able to analyze certain factors (e.g., underlying malignancy and staging, treatment response, cancer treatment prior to PICU admission and start of ECMO, role of HSCT, presence of neutropenia) which are important for clinical decision making. In addition, the indications for both the initiation and discontinuation of ECMO were often not defined, and none of the studies provided risk adjustment for severity of illness or described the outcome of matched children in whom ECMO was not used. Moreover, there is a marked heterogeneity in the oncology patient population. However, due to the lack of granularity of data on underlying malignancies and the small patient numbers, data are insufficient to conduct subgroup analysis. Therefore, the results of this study may not be generalizable to individual oncology patients. The review also included older studies that may not reflect survival in children with oncological diagnoses treated in the modern era. Lastly, another potential limitation of our study was the selection strategy used to avoid overlap between study subjects in registry studies by extraction period. By including the largest study only in case of overlapping study periods may have led to the exclusion of more than necessary non-overlapping subjects for the meta-analysis resulting in a smaller sample size. However, we found that this was a transparent and reliable approach to avoid overlap, which may have introduced even greater bias. In addition, an overlap between centers from the USA participating in more than one registry (ELSO, PEDECOR, and PHIS database) could not be excluded. However, there were only slightly overlapping time periods [28] and different inclusion criteria [30].

Characterization of illness severity, primary malignancy and malignancy status, therapies that were administered (chemotherapy, radiotherapy, surgery, immunotherapy), presence of leukopenia before ECMO, and the ultimate outcome from the malignancy were not reported in the majority of the included studies. It is likely that a large part of the observed range in heterogeneity can be attributed to differences in these variables that are difficult to control for without access to individual patient data.

The risk of bias is difficult to accurately define in metaanalyses of observational studies [42] and is made more challenging because pre-registration and protocol preparation are not mandatory. As a result, data from unpublished studies or partly unpublished results cannot be identified. This may lead to an increased risk of publication bias and other reporting biases such as selective outcome reporting. In addition, only retrospective studies were identified. These have inherent limitations such selection bias and missing data. However, observational studies provide valuable supplementary information regarding safety and long-term outcomes of interventions. Their results might be more directly applicable to a general population as they are conducted under a more real-life setting than RCTs, which usually involve very restricted populations treated with highly standardized care.

Despite the limitations, this review provides an important summary of the published outcomes and complications of ECMO used to support children with oncological diagnoses. This could be used to enlighten discussions between critical care providers and oncologists when faced with a child with cancer who has pulmonary or cardiac dysfunction refractory to conventional care. 


\section{Conclusion}

Overall, aligned with the trend towards improving oncological outcomes, ECMO could represent a viable and ethically justifiable rescue therapy for some of these patients despite the higher mortality compared to the general PICU population. Future studies are needed to refine patient selection and optimize the timing of intervention, and to define patients for whom ECMO may provide benefit or harm [43]. Until these new results become available, data on use of ECMO in this vulnerable patient population remain inconclusive.

\begin{abstract}
Abbreviations
ARDS: Acute respiratory distress syndrome; $\mathrm{Cl}$ : Confidence interval; ECMO: Extracorporeal membrane oxygenation; ELSO: Extracorporeal Life Support Organization; GRADE: Grading of Recommendations, Assessments, Developments and Evaluations; HSCT: Hematopoietic stem cell transplantation; PICU: Pediatric intensive care unit; PRISMA: Preferred Reporting Items for Systematic Reviews and Meta-Analyses.
\end{abstract}

\section{Supplementary Information}

The online version contains supplementary material available at https://doi. org/10.1186/s13613-022-00983-0.

Additional file 1: Table S1. PRISMA-P checklist. Table S2. Search strategy Table S3. Patient characteristics of included studies. Table S4. Indications for ECMO and related hospital mortality. Figure S1. Influence analyses of studies reporting on ECMO mortality. Figure S2. Estimated pooled ECMO mortality when influential studies are excluded. Table S5. Summary result meta-analysis ECMO mortality. Figure S3. Influence analyses studies reporting hospital mortality. Figure $\mathbf{S 4}$. Estimated pooled hospital mortality when influential studies are excluded. Table S6. Summary result metaanalysis hospital mortality. Table S7. Quality Assessment Studies. Figure S5. Funnel plot of studies reporting on ECMO mortality. Figure S6. Funnel plot of studies reporting on hospital mortality. Table S8. Egger's test result for publication bias. Table S9. GRADE assessment.

\section{Acknowledgements}

We do not have acknowledgments.

\section{Authors' contributions}

The study was designed by VS, RH and RW. VS and RH screened the articles and extracted the data. RW and LS assessed the risk of bias. $\mathrm{RH}$ analyzed and interpreted the data under the supervision of RW. Tables and figures were produced by RH and RW. RW had primary responsibility of writing the manuscript. All authors critically revised the manuscript for important intellectual content and approved the final draft. All authors read and approved the final manuscript.

\section{Funding}

The authors received no financial support for the research and authorship.

\section{Availability of data and materials}

All data generated or analyzed during this study are included in the published studies and their additional information files.

\section{Declarations}

Ethics approval and consent to participate

Not applicable.

\section{Consent for publication}

Not applicable.

\section{Competing interests}

The authors declared that they do not have a conflicting interest.

\section{Author details}

${ }^{1}$ Department of Pediatric Intensive Care, University Medical Centre Utrecht/ Wilhelmina Children's Hospital, Lundlaan 6, 3584 EA Utrecht, The Netherlands. ${ }^{2}$ Department of Neonatology and Pediatric Intensive Care, Rigshospitalet, Copenhagen, Denmark. ${ }^{3}$ Pediatric Intensive Care Unit, University Hospital Southampton, Southampton, UK. ${ }^{4}$ Pediatric Intensive Care Unit, Department of Woman's and Child's Health, Padua University Hospital, Padua, Italy. ${ }^{5}$ Department of Woman, Child and Urological Diseases, Pediatric Intensive Care Unit, University-Hospital S. Orsola-Malpighi Policlinic, Bologna, Italy. ${ }^{6}$ Department of Pediatric Intensive Care, Royal Bristol Children's Hospital, Bristol, UK. ${ }^{7}$ Intensive Care, Department of Pediatrics and Pediatric Surgery, Erasmus Medical Centre, Sophia Children's Hospital, Rotterdam, The Netherlands. ${ }^{8}$ Department of Pediatrics, Pediatric Intensive Care Unit, Medical University of Innsbruck, Innsbruck, Austria. ${ }^{9}$ Department of Pediatric Intensive Care, Universitätsklinik Essen, Essen, Germany. ${ }^{10}$ Department of General Pediatrics-Intensive Care Medicine, University Children's Hospital Münster, Munster, Germany. ${ }^{11}$ Department of Pediatric Intensive Care, Ghent University Hospital, Ghent, Belgium.

${ }^{12}$ Department of Pediatric Intensive Care, Newcastle Upon Tyne Hospitals NHS Foundation Trust, Newcastle upon Tyne, UK. ${ }^{13}$ Department of Pediatric Intensive Care, Gaslini Hospital, Genova, Italy. ${ }^{14}$ Pediatric Intensive Care Unit, Ospedale Pediatrico Bambino Gesù, IRCC, Rome, Italy. ${ }^{15}$ Pediatric and Neonatal Intensive Care Unit, Children's Research Centre, University Children's Hospital Zurich and University of Zurich, Zurich, Switzerland.

Received: 15 September 2021 Accepted: 13 January 2022

Published online: 29 January 2022

\section{References}

1. Gatta G, Botta L, Rossi S, Aareleid T, Bielska-Lasota M, Clavel J, et al. Childhood cancer survival in Europe 1999-2007: results of EUROCARE-5-a population-based study. Lancet Oncol. 2014;15:35-47.

2. Soeteman M, Potratz J, Nielsen JSA, Willems J, Valla FV, Brierley J, et al. Research priorities in pediatric onco-critical care: an international Delphi consensus study. Intensive Care Med. 2019;45:1681-3.

3. https://www.elso.org/Registry/SupportDocuments/CenterIDList, Assessed 21 November 2021.

4. Stewart LA, Clarke M, Rovers M, Riley RD, Simmonds M, Stewart G, et al. Preferred reporting items for systematic review and meta-analyses of individual participant data: the PRISMA-IPD statement. JAMA. 2015;313:1657-65.

5. Mueller M, D’Addario M, Egger M, Cevallos M, Dekkers O, Mugglin C, et al. Methods to systematically review and meta-analyse observational studies: a systematic scoping review of recommendations. BMC Med Res Methodol. 2018;18:44.

6. Stroup DF, Berlin JA, Morton SC, Olkin I, Williamson GD, Rennie D, et al. Meta-analysis of observational studies in epidemiology: a proposal for reporting. Meta-analysis of observational studies in epidemiology (MOOSE) group. JAMA. 2000;283:2008-12.

7. Stang A. Critical evaluation of the Newcastle-Ottawa scale for the assessment of the quality of nonrandomized studies in meta-analyses. Eur J Epidemiol. 2010;25:603-5

8. Wells GA, Shea B, OConnell D, Peterson J, Welch V, Losos W, et al. The Newcastle-Ottawa scale (NOS) for assessing the quality of nonrandomised studies in meta-analyses. 2000. http://www.ohri.ca/programs/ clinical_epidemiology/oxford.asp.

9. Guyatt GH, Oxman AD, Kunz R, Woodcock J, Brozek J, Helfand M, Alonso-Coello P, Glasziou P, Jaeschke R, Akl EA, et al. GRADE guidelines: 7. Rating the quality of evidence-inconsistency. J Clin Epidemiol. 2011;64:1294-302.

10. Iorio A, Spencer FA, Falavigna M, Alba C, Lang E, Burnand B, McGinn T, Hayden J, Williams K, Shea B, et al. Use of GRADE for assessment of evidence about prognosis: rating confidence in estimates of event rates in broad categories of patients. BMJ. 2015;350:h870.

11. DerSimonian R, Laird N. Meta-analysis in clinical trials. Control Clin Trials. 1986;7:177-88. 
12. Higgins JP, Thompson SG, Deeks JJ, Altman DG. Measuring inconsistency in meta-analysis. BMJ. 2003;327:557-60.

13. Higgins JPT, Geen S (Eds): Cochrane handbook for systematic reviews of interventions version 5.1.0. The Cochrane Collaboration, 2011. Available at: http://www.cochrane-handbook.org.

14. Baujat B, Mahé C, Pignon JP, Hill C. A graphical method for exploring heterogeneity in meta-analyses: application to a meta-analysis of 65 trials. Stat Med. 2002;21:2641-52.

15. Pignon JP, Bourhis J, Domenge C, Designé L. Chemotherapy added to locoregional treatment for head and neck squamous-cell carcinoma: three meta-analyses of updated individual data. MACH-NC collaborative group. Meta-analysis of chemotherapy on head and neck cancer. Lancet. 2000:355:949-55.

16. Egger M, Davey Smith G, Schneider M, Minder C. Bias in meta-analysis detected by a simple, graphical test. BMJ. 1997;315:629-34.

17. Ramanathan K, Shekar K, Ling RR, Barbaro RP, Wong SN, Tan CS, et al. Extracorporeal membrane oxygenation for COVID-19: a systematic review and meta-analysis. Crit Care. 2021;25:211

18. Ramanathan K, Yeo N, Alexander P, Raman L, Barbaro R, Tan CS, et al. Role of extracorporeal membrane oxygenation in children with sepsis: a systematic review and meta-analysis. Crit Care. 2020;24:684.

19. Lindén V, Karlén J, Olsson M, Palmér K, Ehrén H, Henter Jl, et al. Successful extracorporeal membrane oxygenation in four children with malignant disease and severe Pneumocystis carinii pneumonia. Med Pediatr Oncol. 1999;32:25-31.

20. Gupta M, Shanley TP, Moler FW. Extracorporeal life support for severe respiratory failure in children with immune compromised conditions. Pediatr Crit Care Med. 2008;9:380-5.

21. Gow KW, Heiss KF, Wulkan ML, Katzenstein HM, Rosenberg ES, Heard ML, et al. Extracorporeal life support for support of children with malignancy and respiratory or cardiac failure: the extracorporeal life support experience. Crit Care Med. 2009;37:1308-16.

22. Meister B, Zelger B, Kropshofer G, Klein-Franke A, Crazzolara R, Frühwirth $M$, et al. Extracorporeal membrane oxygenation as a rescue therapy for leukaemic children with pulmonary failure. Br J Haematol. 2010;148:126-31.

23. Di Nardo M, Locatelli F, Palmer K, Amodeo A, Lorusso R, Belliato M, et al. Extracorporeal membrane oxygenation in pediatric recipients of hematopoietic stem cell transplantation: an updated analysis of the extracorporeal life support organization experience. Intensive Care Med. 2014;40:754-6.

24. Smith S, Butt W, Best D, MacLaren G. Long-term survival after extracorporeal life support in children with neutropenic sepsis. Intensive Care Med. 2016:42:942-3.

25. Bailly DK, Reeder RW, Zabrocki LA, Hubbard AM, Wilkes J, Bratton SL, et al. Development and validation of a score to predict mortality in children undergoing extracorporeal membrane oxygenation for respiratory failure: pediatric pulmonary rescue with extracorporeal membrane oxygenation prediction score. Crit Care Med. 2017:45:e58-66.

26. Cortina G, Neu N, Kropshofer G, Meister B, Klingkowski U, Crazzolara R. Extracorporeal membrane oxygenation offers long-term survival in childhood leukemia and acute respiratory failure. Crit Care. 2018;22:222.

27. Maue DK, Hobson MJ, Friedman ML, Moser EAS, Rowan CM. Outcomes of pediatric oncology and hematopoietic cell transplant patients receiving extracorporeal membrane oxygenation. Perfusion. 2019;34:598-604.

28. Steppan DA, Coleman RD, Viamonte HK, Hanson SJ, Carroll MK, Klein OR, et al. Outcomes of pediatric patients with oncologic disease or following hematopoietic stem cell transplant supported on extracorporeal membrane oxygenation: the PEDECOR experience. Pediatr Blood Cancer. 2020:67:e28403

29. Ranta S, Kalzén H, Nilsson A, von Schewelov K, Broman LM, Berner J, et al. Extracorporeal membrane oxygenation support in children with hematological malignancies in Sweden. J Pediatr Hematol Oncol. 2020:43:e272-5.

30. Coleman RD, Goldman J, Moffett B, Guffey D, Loftis L, Thomas J, et al. Extracorporeal membrane oxygenation mortality in high-risk populations: an analysis of the pediatric health information system database. ASAIO J. 2020:66:327-31.

31. Friedman ML, Barbaro RP, Bembea MM, Bridges BC, Chima RS, Kilbaugh $\mathrm{TJ}$, et al. Mechanical ventilation in children on venovenous ECMO. Respi Care. 2020:65:271-80.
32. Pravin RR, Huang BX, Sultana R, Tan CW, Goh KJ, Chan MY, et al. Mortality trends of oncology and hematopoietic stem cell transplant patients supported on extracorporeal membrane oxygenation: a systematic review and meta-analysis. J Intensive Care. 2021;16:8850666211021561.

33. Wohlfarth P, Beutel G, Lebiedz P, Stemmler HJ, Staudinger T, Schmidt M, et al. Characteristics and outcome of patients after allogeneic hematopoietic stem cell transplantation treated with extracorporeal membrane oxygenation for acute respiratory distress syndrome. Crit Care Med. 2017:45:e500-7.

34. Gow KW, Wulkan ML, Heiss KF, Haight AE, Heard ML, Rycus P, et al. Extracorporeal membrane oxygenation for support of children after hematopoietic stem cell transplantation: the extracorporeal life support organization experience. J Pediatr Surg. 2006;41:662-7.

35. Wösten-van Asperen RM, van Gestel JPJ, van Grotel M, Tschiedel E, Dohna-Schwake C, Valla FV, et al. PICU mortality of children with cancer admitted to pediatric intensive care unit a systematic review and metaanalysis. Crit Rev Oncol Hematol. 2019;142:153-63.

36. Bayrakci B, Josephson C, Fackler J. Oxygenation index for extracorporeal membrane oxygenation: is there predictive significance? J Artif Organs. 2007;10:6-9.

37. Trachsel D, McCrindle BW, Nakagawa S, Bohn D. Oxygenation index predicts outcome in children with acute hypoxemic respiratory failure. Am J Respir Crit Care Med. 2005;172:206-11.

38. Polito A, Dupuis-Lozeron E, Barbaro R, Rimensberger PC. Ventilation parameters before extracorporeal membrane oxygenator and in-hospital mortality in children: a review of the ELSO registry. ASAIO J. 2021.

39. Munshi L, Walkey A, Goligher E, Pham T, Uleryk EM, Fan E. Venovenous extracorporeal membrane oxygenation for acute respiratory distress syndrome: a systematic review and meta-analysis. Lancet Respir Med. 2019;7:163-72

40. Carpenter JL, Yu YR, Cass DL, et al. Use of venovenous ECMO for neonatal and pediatric ECMO: a decade of experience at a tertiary children's hospital. Pediatr Surg Int. 2018;34:263-8.

41. Barbaro RP, Paden ML, Guner YS, Raman L, Ryerson LM, Alexander P, et al. Pediatric extracorporeal life support organization registry international report 2016. ASAIO J. 2017;63:456-63.

42. Metelli S, Chaimani A. Challenges in meta-analyses with observational studies. Evid Based Ment Health. 2020;23:83-7.

43. Schlapbach LJ, Chiletti R, Straney L, Festa M, Alexander D, Butt W, et al. Defining benefit threshold for extracorporeal membrane oxygenation in children with sepsis-a binational multicenter cohort study. Crit Care. 2019;23:429.

\section{Publisher's Note}

Springer Nature remains neutral with regard to jurisdictional claims in published maps and institutional affiliations.

\section{Submit your manuscript to a SpringerOpen ${ }^{\circ}$ journal and benefit from:}

- Convenient online submission

- Rigorous peer review

- Open access: articles freely available online

- High visibility within the field

- Retaining the copyright to your article

Submit your next manuscript at $\boldsymbol{\nabla}$ springeropen.com 